\title{
Accuracy Assessment of Duhok City Land use Official Maps
}

\author{
Raad Awad Kattan, Farsat H. Abdulrahman* \\ Department of Surveying Engineering, College of Engineering, University of Duhok, Kurdistan Region, Iraq
}

\section{*Correspondence author: \\ Farsat H. Abdulrahman, \\ Department of Surveying \\ Engineering, College of \\ Engineering, University of \\ Duhok, Kurdistan \\ Region - F.R. Iraq. \\ E-mail: farsat.heeto@uod.ac}

Received: 18 May 2019

Accepted: 03 September 2019

Published: 01 December 2019

DOI

10.25156/pti.v9n2y2019.pp178-185

\section{A B S T R A C T}

In this study, the geometric accuracy of four different maps for three sectors of Duhok city was assessed. The maps were produced in different periods and different techniques. One set of maps was paper plotted maps, which had to be geo-referenced. The other three maps were digitally plotted with reference to the global coordinate system UTM/WGS-84/Zone $38 \mathrm{~N}$ projection. A total of 51 points were identified on one reference map, which is the master plan of Duhok city prepared by the general directorate of urban planning/Kurdistan region/Iraq with the collaboration of the German company Ingenieurburo Vossing Company. The reference map, which is the master plan of Duhok governorate, is an official map that is certified and checked by the ministry of planning of the Kurdistan region to have a positional accuracy of $\pm 1.5 \mathrm{~cm}$. These points were searched for and identified on the other three maps. Discrepancies in Easting and Northings of these points were calculated, which resulted in the mean discrepancy of $2.29 \mathrm{~m}$ with a maximum value of $8.5 \mathrm{~m}$ in one event. The maximum standard deviation in $\mathrm{dE}$ and $\mathrm{dN}$ was $3.8 \mathrm{~m}$. These values are reasonably accepted, considering that the maps were prepared using different techniques and a variable accuracy standard.

Keywords: Assess geometric accuracy; Discrepancy; Geo-referencing; Land use maps

\section{INTRODUCTION}

The aim of this study is to assess the geometric accuracy and quality of the available land-use maps of Duhok city.

In land-use mapping, especially cadastral mapping, large errors cannot be tolerated. Errors here mean financial issues, specifically in expensive commercial districts. The most important expected error sources are: (1) Survey control errors such as traverse closures, differential global positioning system net accuracy and correction, (2) detail surveying errors, (3) plotting errors, and (4) plotting scale.

Old paper cadastral maps were produced using large to medium scales ranging between $1 / 500$ and $1 / 10000$. In contrast, modern digital maps can be produced in any required scale without having a specified limit.

Many authors and organizations tackled the accuracy subject of cadastral maps, (Siriba, 2009, presented an approach to estimate the positional accuracy of a cadastral dataset derived from uncontrolled and un-rectified aerial photography. The survey department of Jamaica, 2000, published the procedures and standards for digital cadastral surveying in Jamaica. In which, the details are listed about responsibilities of the surveyor, instrumentation which are mainly GPS and total stations with their calibration, procedures, and specifications for fieldwork, office work, and information about the main GPS control points as a national calibration network.

Hashim et al., 2016, gave the details of how the Department of Surveying and Mapping of Malaysia modernized and reformed its cadastral legacy datasets by generating an accurate digital-based representation of cadastral parcels. These legacy databases usually are derived from paper parcel maps known as a certified plan. The cadastral modernization will result in the new cadastral database on a global digital map no longer being based on single and static parcel paper maps.

On the other hand, Mustafa et al., 2012, used remote sensing images from different satellite datasets and GIS tools for checking and assessing land-use change in Duhok city, Kurdistan region-Iraq. The results of their study indicated that Duhok city have changed considerably and increased up to $20 \%$ from 1989 to 2012. Furthermore, Mohammed, 2013, used the same technique in such work to show the effect of remote sensing imagery and GIS tools in the mapping of land use and land cover in Duhok city from specific periods of time those being 1998, 2007, and 2011.

For the purpose of this study, three different maps and one orthophoto were used. One map was held as a reference for the 
purpose of comparing the other three maps. These maps were prepared in different periods and used different techniques. Old maps were prepared using the plane table detail survey method and traverse survey with a direct plotting in the field. The other maps were produced using photogrammetric techniques producing vector digital maps. Three sectors of Duhok city were selected. The four maps are available for these sectors. Clear features identified in all of these maps were marked, and their coordinates were measured. The aim is to find the discrepancies among these available maps as well as to find out if these discrepancies are systematic and can be treated using common shift or rotation using different methods. For comparison purposes of old and new maps, it also displayed the growth of the city in the past few decades.

\section{RESOURCES}

For the purpose of this study, the following resources were utilized:

\section{Master Plan, Duhok City}

The design plan of Duhok city is an official map that is certified and checked by the ministry of planning of the Kurdistan region to have a positional accuracy of $\pm 1.5 \mathrm{~cm}$.
The Master Plan Duhok 2032/ land-use plane, Figure 1 was prepared by the general directorate of urban planning/ Kurdistan region/Iraq with the collaboration of the German company called IngenieurburoVossingCompany. The map dated to August 3, 2016 and has a scale of 1/6000 (although in digital maps, the scale is not limited). The map is a UTM geo-referenced vector map. The Zoomed in view of a sector of the map is shown in Figure 2. The preparation of this map is mainly built on details.

This map (the land-use plan) will be used throughout this work as a reference map to check the accuracy of the other maps utilized in this study.

\section{Old Paper Maps}

There are three old paper maps for the three sectors of the city those being: Down Malta, Barushky, and Shakhky area, Figure 3. The maps are differently dated with a scale of $1 / 1000$ written on the title block. They survey was completed using plane table traversing and plane table detail survey using the telescopic alidade instrument.

Figure 4 shows a zoomed in view of part of Down Malta sector. As shown above, the map was drawn on transparent trace paper and drawing ink.

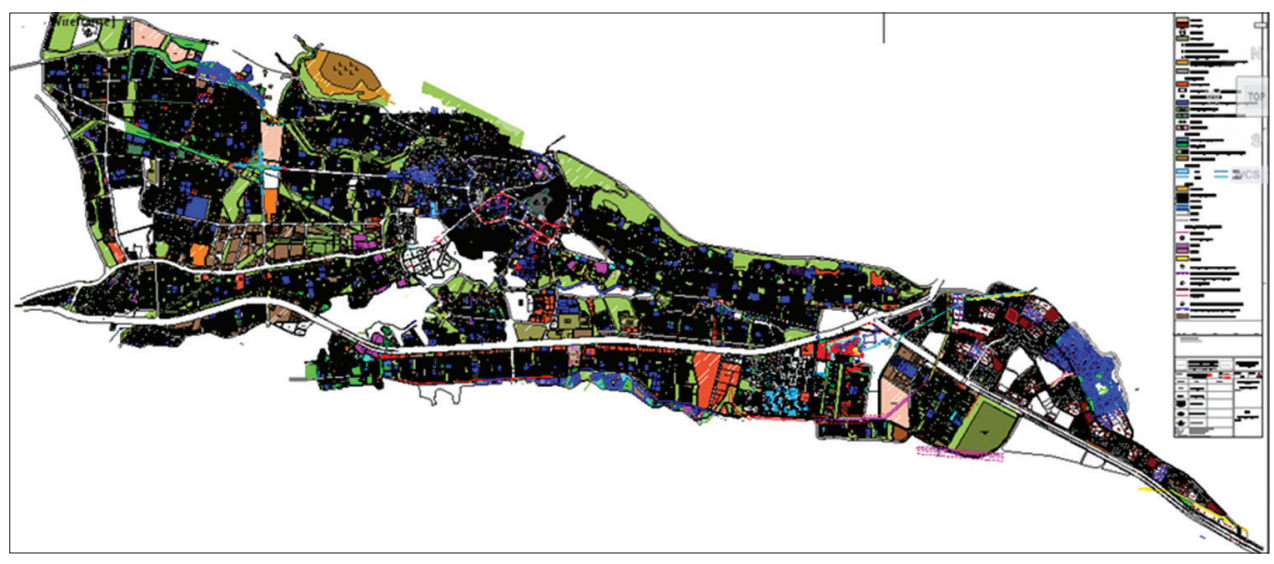

Figure 1: The land-use master plan of Duhok city

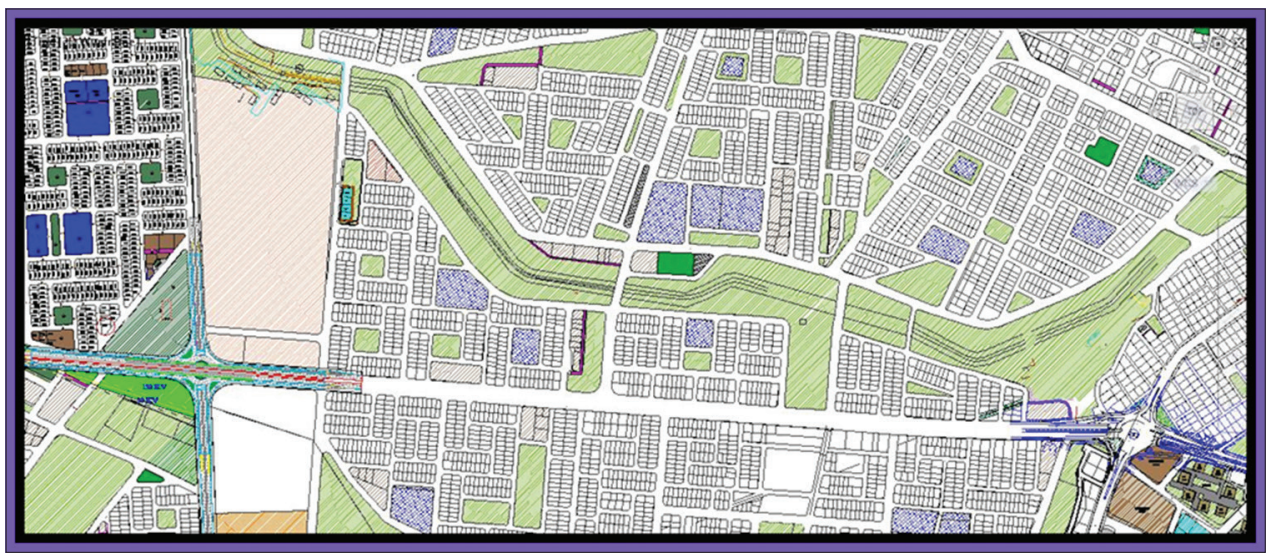

Figure 2: Zoomed in view of the land-use plan/master plan of Duhok city 


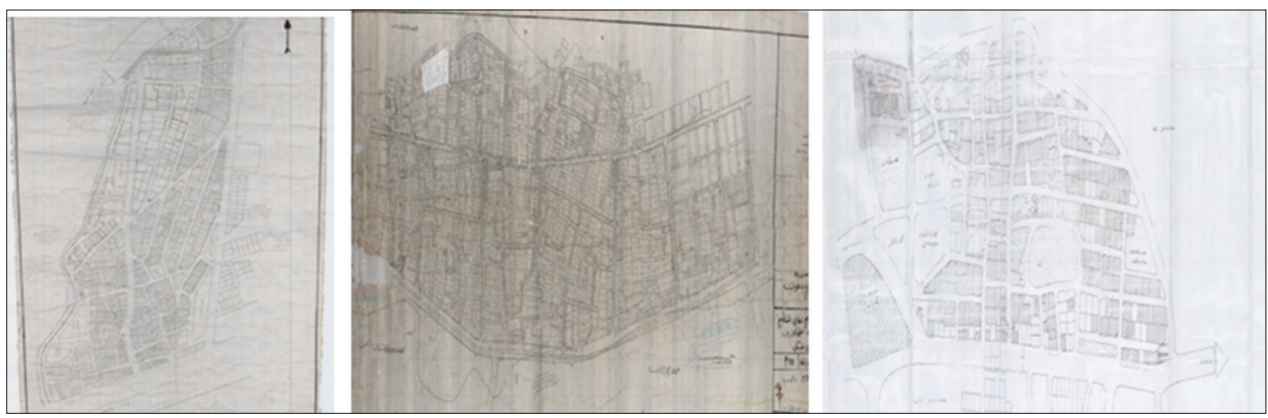

Figure 3: Paper old maps of Down Malta, Barushky, and Shakhky

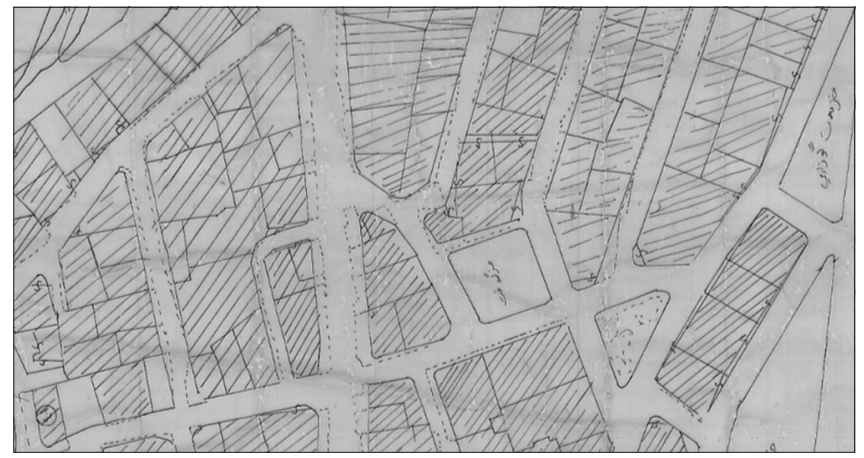

Figure 4: Zoomed in view on part of Down Malta, old map

The maps were scanned and geo-referenced based on common control points with the land-use plan. Nine control points were used for Down Malta map, six points for Barushky, and five points for Shakhky sectors. For geo-referencing, the Global Mapper software was used. Then, the three maps were put in the UTM coordinate system. The range of accuracy of the geo-referencing procedure is shown in Table 1.

\section{Aerial Survey Map}

Aerial survey map was produced by the Vossing German Company in 2011 and digitized by the directorate of municipality of Duhok city Figure 5.

The map is geo-referenced to UTM projection. It is a topographic vector map based on extensive aerial survey which shows contour lines, roads, and building details. Figure 6 enlarged view to a part of this map.

\section{Orthophoto Map}

The orthophoto map was produced by the Vossing German Company, Figure 7 dated to the year 2011. The image is a mosaic of rectified aerial photos. Rectification makes the photos vertical with the correct scale and orientation. The orthophoto is a geo-referenced digital image.

\section{METHODOLOGY AND MEASUREMENTS}

The AutoCAD Civil 3D 2019 software was used as a measuring and recording tool. The Master Plan
Table 1: Standard deviation of geo-referencing accuracy

\begin{tabular}{lcccc}
\hline Sectors & $\begin{array}{c}\text { Number of } \\
\text { GCPs for Geo- } \\
\text { referencing }\end{array}$ & $\begin{array}{c}\text { Number of } \\
\text { GCPs for } \\
\text { Checking }\end{array}$ & \multicolumn{2}{c}{$\begin{array}{c}\text { Geo-referencing } \\
\text { accuracy }\end{array}$} \\
\cline { 5 - 6 } & 9 & 5 & $\begin{array}{c}\text { Std. E } \\
(\mathbf{m})\end{array}$ & $\begin{array}{c}\text { Std. N } \\
(\mathbf{m})\end{array}$ \\
\hline Down malta & 9 & 5 & 1.652 & 0.907 \\
Barushky & 6 & 5 & 1.035 & 2.303 \\
Shakhky & 5 & & & \\
\hline
\end{tabular}

Duhok map was loaded, and the other maps were superimposed on that map each in its turn. This was accomplished for the three chosen locations in the city mentioned above. These sectors appear on the four available maps, all of which are geo-referenced to UTM projection.

Clear points such as building corners or street intersections were chosen and identified on each of the four maps. The selected points were given a serial number related to the sector and the map. Once the point was identified and marked on the map, its coordinate was stored and listed in AutoCAD civil 3D of the three sectors, as shown in Figure 8.

The measured coordinates were exported to an excel datasheet. Table 2 shows part of the datasheet, which is a sample of the measure coordinates on the three maps for one sector. The points are listed according to their serial number in the group, Northing and Easting of the points, elevations which are assigned to zero, and the point's descriptions which are related to the sector and the map type.

A total of 182 coordinates value were recorded, with 51 points used as a reference and the other 131 points were used as checkpoints. Some points could not be identified on all the four maps; therefore, the number of the selected points dropped down.

The discrepancies described as a length equals $\sqrt{ }\left((\Delta \mathrm{E})^{2}\right.$ $\left.+(\Delta \mathrm{N})^{2}\right)$ are tabulated in Table 2 , column 11. The discrepancies direction, which is expressed as azimuths, is calculated as $=\operatorname{ATAN}(\Delta \mathrm{E} / \Delta \mathrm{N})$ and adjusted to the right 


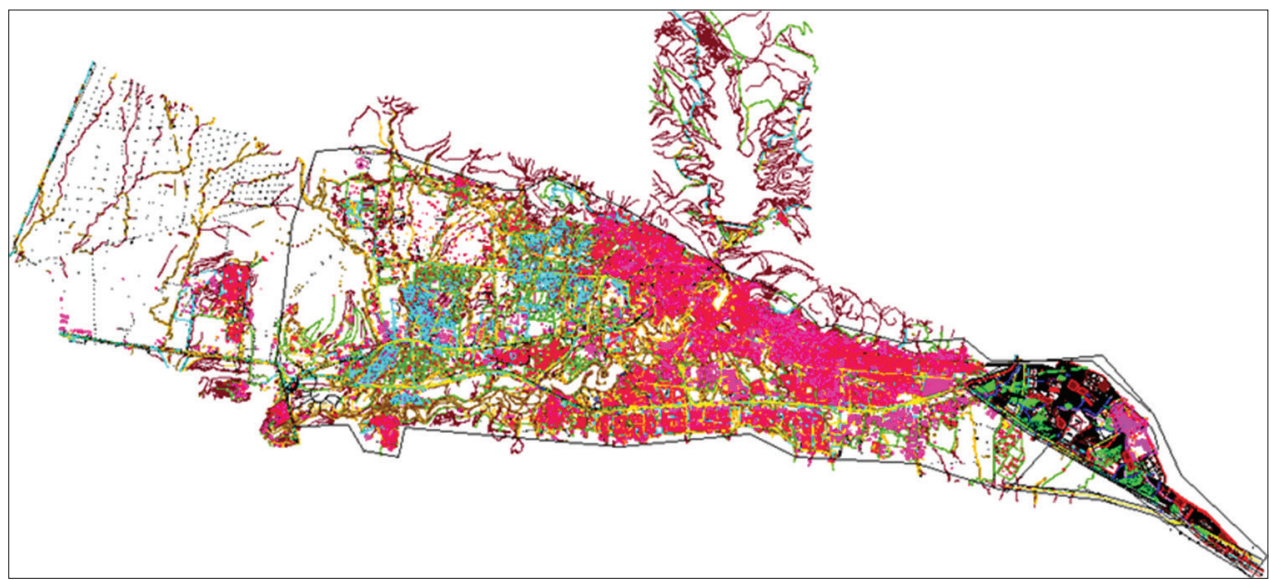

Figure 5: Aerial survey map

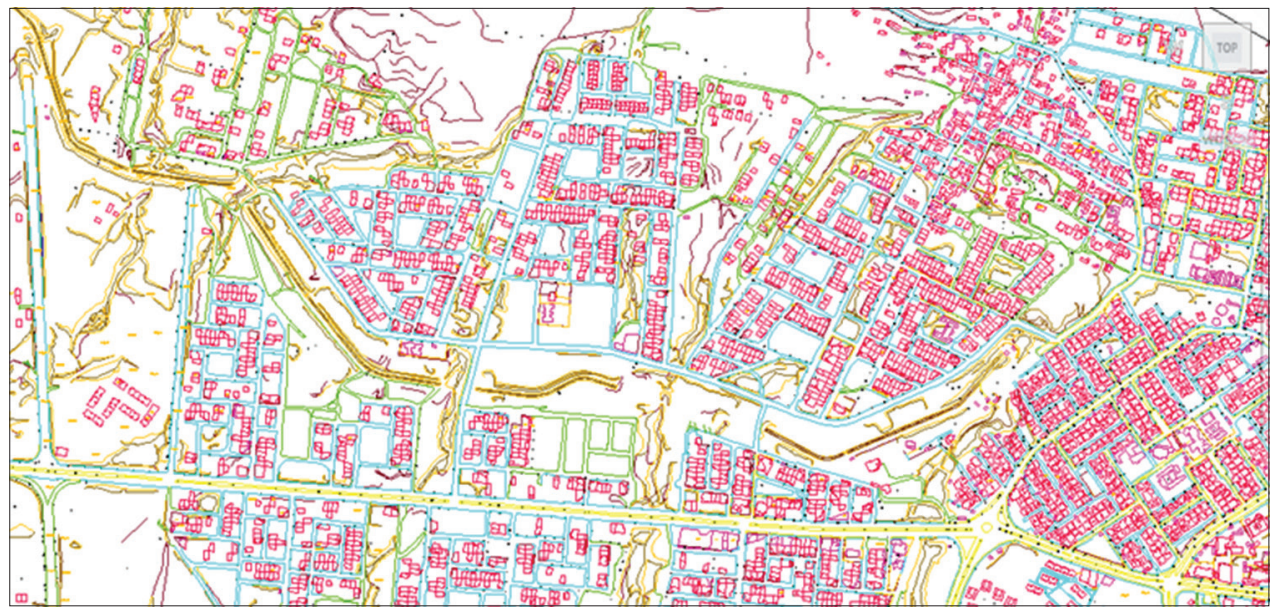

Figure 6: A zoomed in view to a part of the aerial survey map

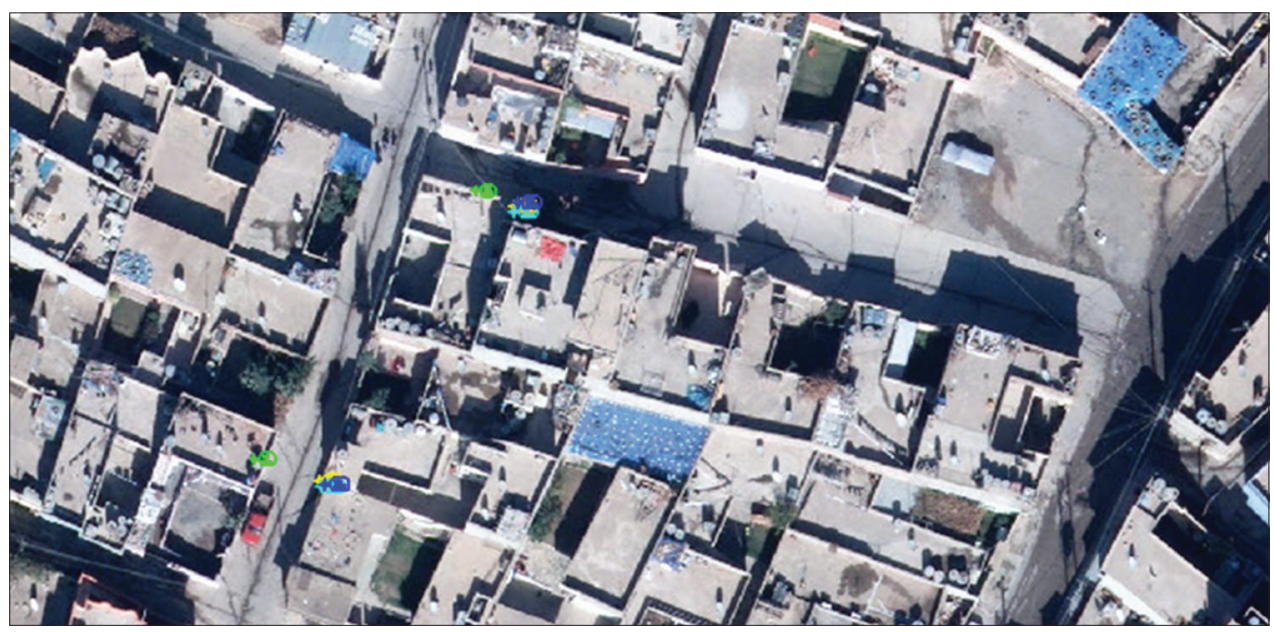

Figure 7: A sample of a zoomed in view to a part of the orthopho of Barashoky overlain the selected points

quadrant by adding or subtracting $180^{\circ}$ or subtracting from $360^{\circ}$.

A $(3 \sigma)$ rejection limit was used to sieve large discrepancies in easting and northing. Few points were dropped from the list, and calculations were carried out again.

\section{DISCUSSION OF THE RESULTS}

The Master Plan Duhok 2032 is used as a reference for comparison. The coordinates of each point on the other map is subtracted from its corresponding reference coordinate. Table 3 shows a sample of the data and results for Barushky sector. 


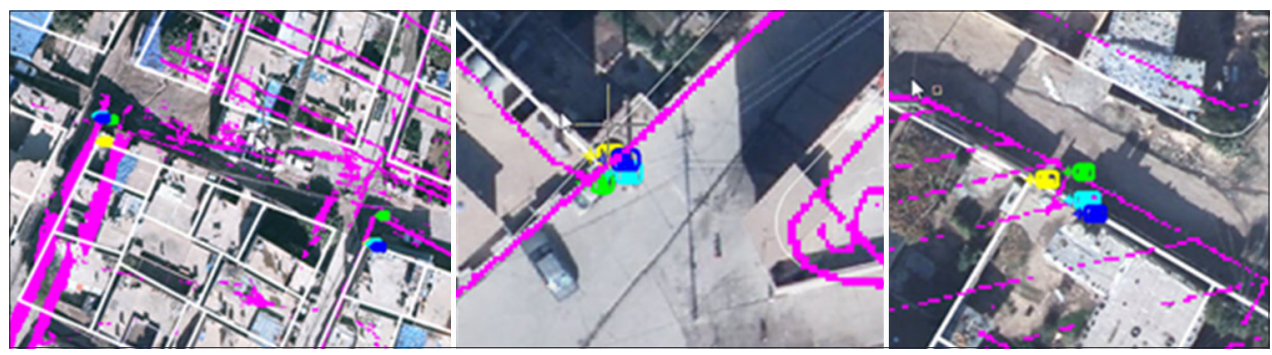

Figure 8: Samples of zoomed in views to a part of all the selected maps of Barashoky, Downmalta, and Shakhky overlain the selected points

Table 2: Part of the coordinate list for all measured points

\begin{tabular}{|c|c|c|c|c|c|c|c|c|c|c|c|c|c|c|}
\hline \multicolumn{5}{|c|}{ Down Malta design map points } & \multicolumn{5}{|c|}{ Down Malta old map points } & \multicolumn{5}{|c|}{ Down Malta sky map points } \\
\hline 1 & 4080160.202 & 315473.748 & 0.000 & DM1 & 1 & 4080161.737 & 315469.583 & 0.000 & A1 & 1 & & & & SM1 \\
\hline 2 & 4080172.322 & 315632.781 & 0.000 & DM2 & 2 & 4080176 & 31562 & 00 & $\mathrm{~A} 2$ & 2 & 4080170.329 & 315630.311 & 0.000 & \\
\hline 3 & 4080219.121 & 315763.970 & 0.000 & DM3 & 3 & 14 & & 00 & A3 & 3 & & & & \\
\hline 4 & 4080206.377 & 315321.030 & 0.000 & DM4 & 4 & 206.840 & 315323.294 & 00 & A4 & 4 & 83 & 953 & 0.000 & \\
\hline 5 & 4080263.023 & 315801.567 & 0.000 & DM5 & 5 & & & & A5 & 5 & & & 0.000 & \\
\hline 6 & 4080365.043 & 315615.320 & 0.000 & DM6 & 6 & $40 \varepsilon$ & 315 & 0 & A6 & 6 & & & & SM6 \\
\hline 7 & 4080 & 806 & 0.000 & DM7 & 7 & 48 & & & A7 & 7 & 330 & 867 & 0.000 & SM7 \\
\hline 8 & 4080 & 349 & 0.000 & DM8 & 8 & 66 & 93 & 0 & A8 & 8 & & & & SM8 \\
\hline 9 & 4080517.082 & 315704.901 & 0.000 & DM9 & 9 & 408 & 3157 & & A9 & 9 & 35 & & 0.000 & SM9 \\
\hline 10 & 4080551.525 & 315 & 0.000 & M10 & 10 & 64 & & & A10 & 10 & & & & \\
\hline 11 & 4080671.665 & 315766.598 & 0.000 & M11 & 11 & 408 & 315 & 0.000 & A11 & 11 & 94 & & 0.000 & SM11 \\
\hline 12 & 4080 & 315 & 0.000 & M12 & 12 & & & & A12 & 12 & 75 & & 0.000 & 12 \\
\hline 13 & 4080 & 315 & 0.000 & 3 & 13 & & & & A13 & 13 & 4080 & 54 & 0.000 & \\
\hline 14 & 4080 & 21 & 0.000 & M14 & 14 & 01 & 39 & & A14 & 14 & 4080 & & 0.000 & SM14 \\
\hline 15 & 40 & 315982. & 0. & & 5 & 4080816.037 & 315981.442 & & A15 & 15 & & & & \\
\hline \multicolumn{5}{|c|}{ Barushky design map points } & \multicolumn{5}{|c|}{ Barushky old map points } & \multicolumn{5}{|c|}{ Barushky sky map points } \\
\hline 1 & 4080567.710 & 323751.091 & 0.000 & DB1 & 1 & 0570.986 & & 0000 & B1 & 1 & 0569.694 & 96 & & \\
\hline 2 & 4080 & 3237 & 0.000 & DB2 & 2 & 40 & 35 & & B2 & 2 & 29 & 530 & .000 & SM2 \\
\hline 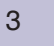 & 4080594.237 & 3234 & 0.000 & DB3 & 3 & & & & & 3 & & 280 & & \\
\hline 4 & 4080 & 323 & 0.000 & DB4 & 4 & 87 & 73 & 0 & B4 & 4 & 82 & 39 & 0.000 & SM4 \\
\hline 5 & 4080779.734 & 3.648 & 0.000 & DB5 & 5 & 351 & 32 & & B5 & 5 & 4080790 & 323600.648 & 0.000 & SM5 \\
\hline 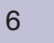 & 4080768.243 & 3234 & 0.000 & DB6 & 6 & 4080 & 32 & & B6 & 6 & 4080767.721 & 323462.008 & & SM6 \\
\hline 7 & 4080789.360 & 323464.082 & 0.000 & DB7 & 7 & & & & B/ & 7 & & & 0 & SM7 \\
\hline 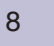 & 4080521.739 & 323286.439 & 0.000 & DB8 & 8 & 4080514.945 & 323286.830 & & B8 & 8 & 4080517.635 & 323289.151 & & SM8 \\
\hline 9 & 4080574.475 & 323245.951 & 0.000 & DB9 & 9 & 4080572.594 & 323237.610 & 0.000 & B9 & 9 & 4080573.343 & 323245.994 & 0.000 & SM9 \\
\hline 10 & 4080619.645 & 323269.658 & 0.000 & DB10 & 10 & 4080617.832 & 323262.916 & 0.0 & B10 & 10 & & 323269.821 & & SM10 \\
\hline 11 & 4080654.449 & 323121.263 & 0.000 & DB11 & 11 & 4080653.255 & 323114.238 & 0.000 & B11 & 11 & 4080653.428 & 323121.554 & 0.000 & SM11 \\
\hline 12 & 4080707.612 & 323165.265 & 0.000 & DB12 & 12 & 4080709.654 & 323159.174 & 0.000 & B12 & 12 & 4080707.103 & 323165.490 & 0.000 & SM12 \\
\hline
\end{tabular}

In this table, the coordinates of the old map points are subtracted from the reference points coordinates. The results are as follows:

a. The differences in northing and easting in meters are tabulated in columns 9 and 10 , respectively. The mean value of the discrepancies in easting and northing is given at the end of each column. Furthermore, the corresponding standard deviations are given.

b. These discrepancies in azimuths are tabulated in column 12. At the end of column 12, the mean discrepancy azimuth from the reference map is $170.569^{\circ}$.

Table 4 shows an abstract of discrepancy means and standard deviations of all maps with reference to the base map; "The Master Plan Duhok."
The mean differences in northings and eastings appear small as the sum of positive and negative large values accumulate to small values. The average of the resultant discrepancies, $\sqrt{ }\left((\Delta \mathrm{E})^{2}+(\Delta \mathrm{N})^{2}\right)$ of all the 131 points $=2.29 \mathrm{~m}$.

The maximum resultant of discrepancy reached $8.5 \mathrm{~m}$ in one event in all of the 131 measured points. This value $(8.5 \mathrm{~m})$ does not represent the whole differences obtained. Figure 9 shows the resultant discrepancies as a length and direction drawn for the old Duhok maps with reference to the Master Plan of Duhok for all three sectors. The lengths of the discrepancies were exaggerated by multiplying with a factor of 10 .

Figure 9 shows the almost systematic nature of the directions of the discrepancies. For Barushky sector, 16 
Table 3: A sample of the data and results for Barushky sector

\begin{tabular}{|c|c|c|c|c|c|c|c|c|c|c|c|c|c|}
\hline \multicolumn{5}{|c|}{ Barushky design map points } & \multicolumn{5}{|c|}{ Barushky old map points } & \multirow{2}{*}{$\frac{\Delta \mathbf{N}}{3.276}$} & \multirow{2}{*}{$\frac{\Delta \mathrm{E}}{-3.436}$} & \multirow{2}{*}{$\begin{array}{c}\text { Length } \\
4.747\end{array}$} & \multirow{2}{*}{$\begin{array}{l}\text { Azimuth } \\
133^{\circ} 38^{\prime} 4^{\prime \prime}\end{array}$} \\
\hline 1 & 4080567.710 & 323751.091 & 0.000 & DB1 & 1 & 4080570.986 & 323747.655 & 0.000 & B1 & & & & \\
\hline 2 & 4080782.856 & 323739.147 & 0.000 & DB2 & 2 & 4080776.196 & 323735.235 & 0.000 & B2 & -6.661 & -3.913 & 7.725 & $210^{\circ} 25^{\prime} 47^{\prime \prime}$ \\
\hline 3 & 4080594.237 & 323495.125 & 0.000 & DB3 & 3 & 4080589.052 & 323493.305 & 0.000 & B3 & -5.185 & -1.821 & 5.495 & $199^{\circ} 20^{\prime} 57^{\prime \prime}$ \\
\hline 4 & 4080738.987 & 323573.817 & 0.000 & DB4 & 4 & 4080729.887 & 323572.173 & 0.000 & B4 & -9.100 & -1.644 & 9.247 & $190^{\circ} 14^{\prime} 24^{\prime \prime}$ \\
\hline 5 & 4080779.734 & 323593.648 & 0.000 & DB5 & 5 & 4080787.851 & 323597.390 & 0.000 & B5 & 8.117 & 3.742 & 8.938 & $24^{\circ} 45^{\prime} 5^{\prime \prime}$ \\
\hline 6 & 4080768.243 & 323461.794 & 0.000 & DB6 & 6 & 4080765.298 & 323458.343 & 0.000 & B6 & -2.945 & -3.452 & 4.538 & $229^{\circ} 31^{\prime} 28^{\prime \prime}$ \\
\hline 7 & 4080789.360 & 323464.082 & 0.000 & DB7 & 7 & 4080786.205 & 323460.796 & 0.000 & B7 & -3.156 & -3.286 & 4.556 & $226^{\circ} 9^{\prime} 38^{\prime \prime}$ \\
\hline 8 & 4080521.739 & 323286.439 & 0.000 & DB8 & 8 & 4080514.945 & 323286.830 & 0.000 & B8 & -6.793 & 0.392 & 6.805 & $176^{\circ} 42^{\prime} 0^{\prime \prime}$ \\
\hline 9 & 4080574.475 & 323245.951 & 0.000 & DB9 & 9 & 4080572.594 & 323237.610 & 0.000 & B9 & -1.881 & -8.341 & 8.551 & $257^{\circ} 17^{\prime} 30^{\prime \prime}$ \\
\hline 10 & 4080619.645 & 323269.658 & 0.000 & DB10 & 10 & 4080617.832 & 323262.916 & 0.000 & B10 & -1.813 & -6.742 & 6.982 & $254^{\circ} 57^{\prime} 1^{\prime \prime}$ \\
\hline 11 & 4080654.449 & 323121.263 & 0.000 & DB11 & 11 & 4080653.255 & 323114.238 & 0.000 & B11 & -1.194 & -7.025 & 7.126 & $260^{\circ} 21^{\prime} 2^{\prime \prime}$ \\
\hline 12 & 4080707.612 & 323 & 0.0 & & 12 & & & & & & -6.091 & & $251^{\circ} 28^{\prime} 13^{\prime \prime}$ \\
\hline 13 & 4080870.891 & 323185.681 & 0.000 & DB13 & 13 & 4080870.262 & 323184.380 & 0.000 & B13 & -0.629 & -1.301 & 1.444 & $244^{\circ} 12^{\prime} 11^{\prime \prime}$ \\
\hline 14 & 4080906.894 & 323215.250 & 0.000 & DB14 & 14 & 4080906.670 & 323212.517 & 0.000 & B14 & -0.224 & -2.732 & 2.742 & $265^{\circ} 18^{\prime} 56^{\prime \prime}$ \\
\hline 15 & 4080733.751 & 323183.802 & 0.000 & DB15 & 15 & 4080735.221 & 323180.203 & 0.000 & B15 & 1.469 & -3.598 & 3.887 & $112^{\circ} 12^{\prime} 50^{\prime \prime}$ \\
\hline 16 & 4080630.089 & 322950.300 & 0.000 & DB16 & 16 & 4080625.382 & 322946.913 & 0.000 & B16 & -4.707 & -3.388 & 5.799 & $215^{\circ} 44^{\prime} 42^{\prime \prime}$ \\
\hline 17 & 4080684.501 & 322979.635 & 0.000 & DB17 & 17 & 4080682.624 & 322973.370 & 0.000 & B17 & -1.877 & -6.265 & 6.540 & $253^{\circ} 19^{\prime} 16^{\prime \prime}$ \\
\hline 18 & 4080790.427 & 322807.597 & 0.000 & DB18 & 18 & 4080787.080 & 322804.623 & 0.000 & B18 & -3.347 & -2.973 & 4.477 & $221^{\circ} 36^{\prime} 46^{\prime \prime}$ \\
\hline 19 & 4080980.489 & 322807.955 & 0.000 & DB19 & 19 & 4080982.937 & 322812.483 & 0.000 & B19 & 2.448 & 4.528 & 5.147 & $61^{\circ} 36^{\prime} 12^{\prime \prime}$ \\
\hline 20 & 4081121.255 & 322734.167 & 0.000 & DB20 & 20 & 4081126.118 & 322736.229 & 0.000 & B20 & 4.863 & 2.062 & 5.282 & $22^{\circ} 58^{\prime} 42^{\prime \prime}$ \\
\hline 21 & 4081161.666 & 322764.398 & 0.000 & DB21 & 21 & 4081166.746 & 322767.875 & 0.000 & B21 & 5.080 & 3.477 & 6.156 & $34^{\circ} 23^{\prime} 22^{\prime \prime}$ \\
\hline 22 & 4081139.130 & 322686.975 & 0.000 & DB22 & 22 & 4081142.975 & 322688.233 & 0.000 & B22 & 3.844 & 1.258 & 4.045 & $18^{\circ} 7^{\prime} 9^{\prime \prime}$ \\
\hline 23 & 4080437.929 & 323829.243 & 0.000 & DB23 & 23 & 4080436.494 & 323824.981 & 0.000 & B23 & -1.435 & -4.262 & 4.497 & $251^{\circ} 23^{\prime} 10^{\prime \prime}$ \\
\hline 24 & 4080614.355 & 323855.126 & 0.000 & DB24 & 24 & 4080616.847 & 323853.372 & 0.000 & B24 & 2.492 & -1.754 & 3.047 & $144^{\circ} 51^{\prime} 57^{\prime \prime}$ \\
\hline \multirow[t]{3}{*}{25} & 4080408.400 & 323996.962 & 0.000 & DB25 & 25 & 4080415.017 & 323997.381 & 0.000 & B25 & 6.617 & 0.419 & 6.630 & $3^{\circ} 37^{\prime} 30^{\prime \prime}$ \\
\hline & & & & & & & & & Mean & -0.428 & -2.246 & Mean & 170.569 \\
\hline & & & & & & & & & SD & 4.427 & 3.388 & & \\
\hline
\end{tabular}

Table 4: Abstract of the mean discrepancies and standard deviations in $\mathrm{N}$ and $\mathrm{E}$

\begin{tabular}{|c|c|c|c|c|c|c|}
\hline \multirow[t]{2}{*}{ Sector } & \multicolumn{6}{|c|}{ Type of map } \\
\hline & \multicolumn{2}{|c|}{ Old map } & \multicolumn{2}{|c|}{ Aerial survey map } & \multicolumn{2}{|c|}{ Orthophoto map } \\
\hline \multirow[t]{3}{*}{ Down Malta } & \multicolumn{2}{|c|}{$\mathrm{N}=15$} & \multicolumn{2}{|c|}{$\mathrm{N}=10$} & \multicolumn{2}{|c|}{$\mathrm{N}=10$} \\
\hline & $\Delta \mathrm{N}=-0.019$ & $\Delta \mathrm{E}=-1.147$ & $\Delta \mathrm{N}=--0.250$ & $\Delta \mathrm{E}=--0.250$ & $\Delta \mathrm{N}=--0.255$ & $\Delta \mathrm{E}=--0.029$ \\
\hline & $\sigma \mathrm{N}=2.035$ & $\sigma \mathrm{E}=2.533$ & $\sigma \mathrm{N}=0.981$ & $\sigma \mathrm{E}=1.144$ & $\sigma \mathrm{N}=0.474$ & $\sigma \mathrm{E}=1.526$ \\
\hline \multirow[t]{3}{*}{ Barushky } & \multicolumn{2}{|c|}{$\mathrm{N}=25$} & \multicolumn{2}{|c|}{$\mathrm{N}=25$} & \multicolumn{2}{|c|}{$\mathrm{N}=23$} \\
\hline & $\Delta \mathrm{N}=--0.422$ & $\Delta \mathrm{E}=-2.532$ & $\Delta \mathrm{N}=-0.097$ & $\Delta \mathrm{E}=-0.232$ & $\Delta \mathrm{N}=--0.161$ & $\Delta \mathrm{E}=-0.303$ \\
\hline & $\sigma \mathrm{N}=3.756$ & $\sigma \mathrm{E}=3.289$ & $\sigma \mathrm{N}=2.158$ & $\sigma \mathrm{E}=0.841$ & $\sigma \mathrm{N}=1.694$ & $\sigma \mathrm{E}=0.781$ \\
\hline \multirow[t]{3}{*}{ Shakhky } & \multicolumn{2}{|c|}{$\mathrm{N}=11$} & \multicolumn{2}{|c|}{$\mathrm{N}=6$} & \multicolumn{2}{|c|}{$\mathrm{N}=6$} \\
\hline & $\Delta \mathrm{N}=-0.079$ & $\Delta \mathrm{E}=--0.898$ & $\Delta \mathrm{N}=--0.872$ & $\Delta \mathrm{E}=-0.341$ & $\Delta \mathrm{N}=--1.076$ & $\Delta \mathrm{E}=--0.807$ \\
\hline & $\sigma \mathrm{N}=1.239$ & $\sigma \mathrm{E}=1.628$ & $\sigma \mathrm{N}=0.952$ & $\sigma \mathrm{E}=1.273$ & $\sigma \mathrm{N}=0.733$ & $\sigma \mathrm{E}=1.498$ \\
\hline
\end{tabular}

All units are in meter

out of the 25 discrepancy values are pointing south to south-west. The mean value for all points was $170^{\circ} 35^{\prime}$.

Old Duhok maps were only chosen as a sample of the discrepancy values to be shown in Figure 9, as these values are the largest to be drawn compared with other maps.

\section{CONCLUSION AND RECOMMENDATION}

\section{The Quality of Maps}

The quality of the maps varies between poor for old paper plotted maps to fair for the newly made digital maps,
Figure 10. All maps are suffering lack of parcels numbers. In aerial survey maps, parcels were drawn by tracing over the aerial photos of the area.

\section{Recommendations}

Most districts of Duhok city are newly built except the old City Centre since the majority of land used within the city is for housing. Most private houses, which usually have standard dimensions of $10 \times 20 \mathrm{~m}$, were built during the last two decades. The parcels sub-divisions are so organized that it is worth to establish well designed cadastral maps that show parcel numbers, segments lengths, and bearings with reference points as this is the case in all modern cadastral 


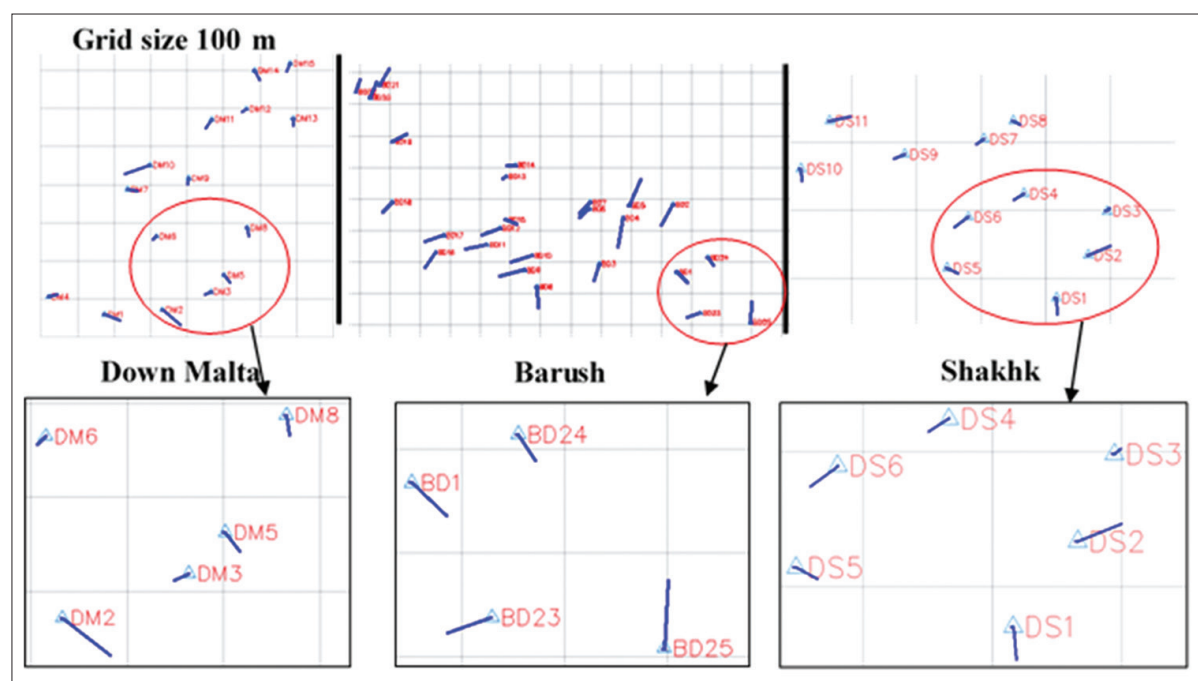

Figure 9: AutoCAD presentation of discrepancy values and directions. (Discrepancy length is enlarged by a factor of 10)

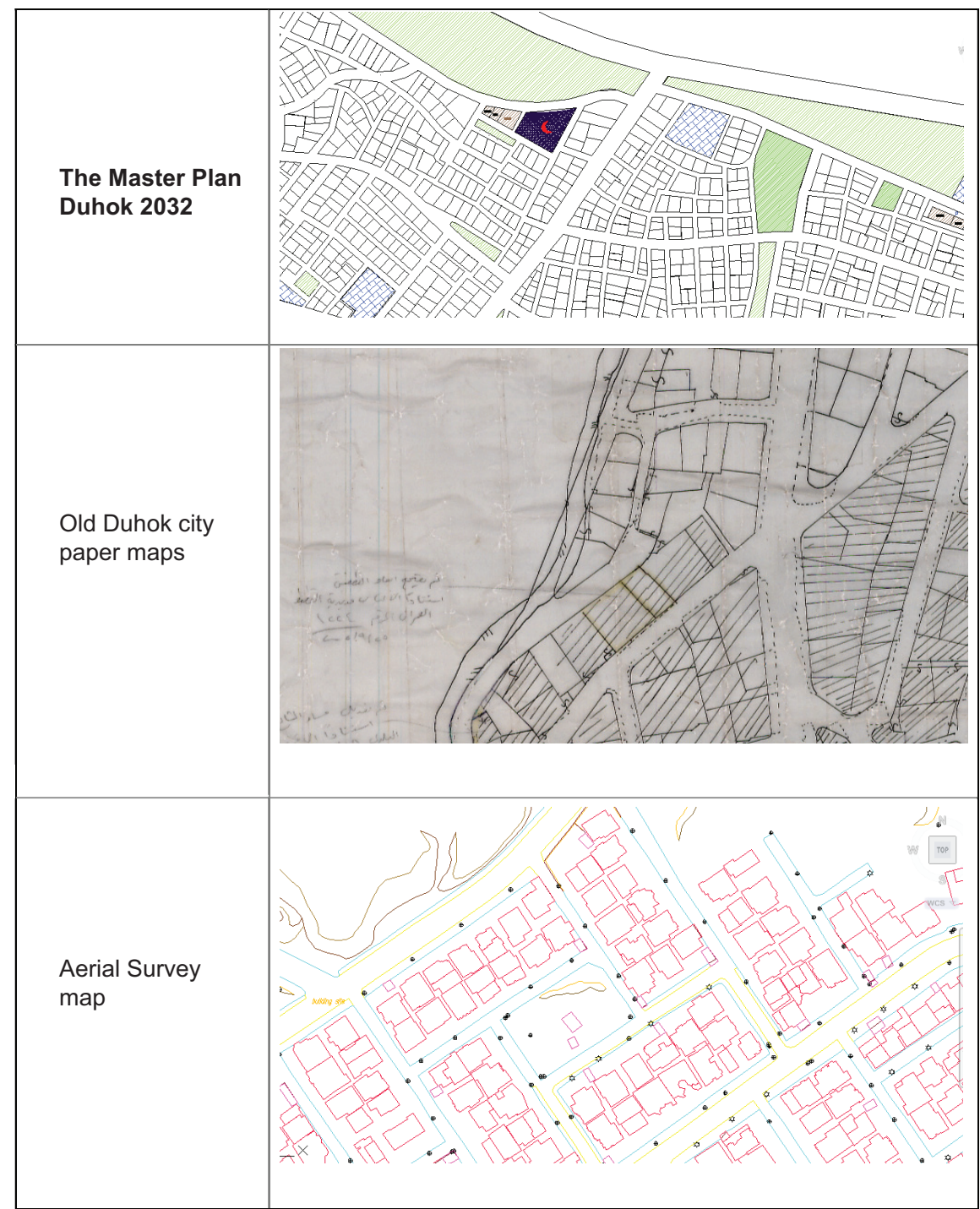

Figure 10: Samples of the available maps for the study 


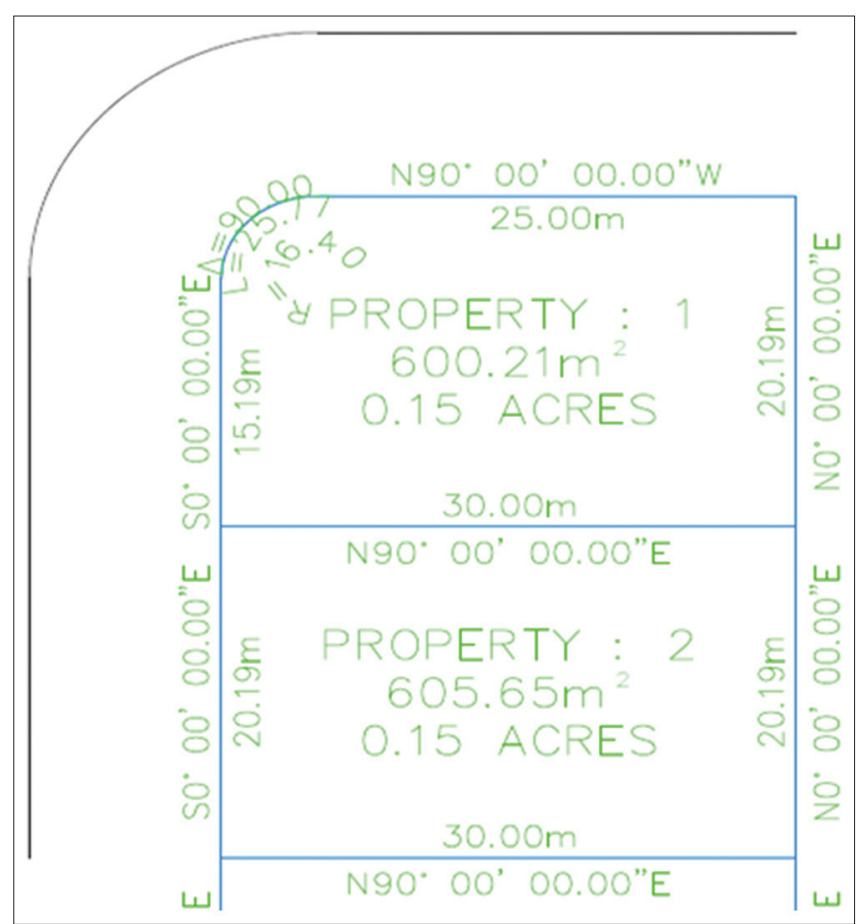

Figure 11: Sample of property map divisions using the AutoCAD software

maps around the world. The AutoCAD software can change any land subdivision into parcels, as shown in Figure 11.

The old Duhok maps drawn on trace papers will soon lose its value; thus, it is prominent that these maps are restored, archived, and changed into vector maps as they contain a lot of important information regarding properties and land use.
Standards and specifications for cadastral surveying and mapping must be prepared regarding the recent developments in measurements and plotting.

\section{ACKNOWLEDGMENT}

The authors are thankful to the staff of the directorate of the municipality of Duhok city, Kurdistan region, Iraq, for providing old paper maps, aerial survey, and orthophotos maps.

\section{REFERENCES}

Hashim, N. M., A. H. Omar, K. M. Omar, N. M. Abdullah and M. H. Yatim. 2016. Cadastral Positioning Accuracy Improvement: A Case Study in Malaysia. International Conference on Geomatic and Geospatial Technology (GGT), 2016. The International Archives of the Photogrammetry, Remote Sensing and Spatial Information Sciences, Kuala Lumpur, Malaysia.

Jamaica, S. D. O. 2000. A Report, Procedures and Standards for Digital Cadastral Surveying in Jamaica. The Land Administration and Management Program.

Mohammed, J. 2013. Land use and cover change assessment using remote sensing and GIS: Dohuk City, Kurdistan, Iraq (19982011). Int. J. Geomatics Geosci. 3(3): 552-569.

Mustafa, Y., R. Ali and R. Najimaldeen. 2012. Monitoring and evaluating land cover change in the Duhok city, Kurdistan regionIraq, by using remote sensing and GIS. Int. J. Eng. Inventions. 1(11): 28-33.

Siriba, D. 2009. Positional Accuracy Assessment of a Cadastral Dataset Based on the Knowledge of the Process Steps Used. $12^{\text {th }}$ AGILE International Conference on Geographic Information Science. Leibniz Universität Hannover, Germany. 